\title{
Treatment of acute myocardial infarction with anisoylated plasminogen streptokinase activator complex
}

\author{
S IKRAM, S LEWIS, C BUCKNALL, I SRAM, N THOMAS, R VINCENT, \\ D CHAMBERLAIN
}

\begin{abstract}
A controlled trial in 149 patients admitted to a district hospital with probable myocardial infarction tested the effect of 30 units of anisoylated plasminogen streptokinase activator complex (APSAC) on indices of infarct size. Patients were grouped prospectively according to whether they entered the trial within two and a half hours (early entry) or between two and a half and four hours (late entry) after onset of the symptoms. Sixty seven of 73 patients in the control group showed increased plasma activity of myocardial creatine kinase isoenzyme that was diagnostic of infarction compared with only 60 of 76 who received APSAC. The difference was significant overall but occurred predominantly in the early entry group. The patients who received APSAC had more early ventricular arrhythmias, compatible with reperfusion, and showed greater preservation of $R$ waves during admission to hospital. Unwanted effects were generally minor and more common in the actively managed group than the control group (26\% v3\%). After nine to 12 months of follow up 12 patients in the control group had died compared with seven in the actively managed group.

The ease of administration and the apparent efficacy of APSAC suggest that it is suitable for use in a district hospital for patients with suspected acute myocardial infarction.
\end{abstract}

\section{Introduction}

Thrombus obstructing an atherosclerotic artery is the commonest precipitating cause of acute transmural myocardial infarction. ${ }^{12}$ When intravenous streptokinase was introduced nearly 30 years ago it seemed a logical treatment to use early in an attack; the first paper on this was published in $1959 .^{3}$ Although early results were promising, ${ }^{45}$ subsequent studies, including Australian and British multicentre trials, ${ }^{67}$ did not show any evidence of benefit from this treatment, and it was not used much outside mainland Europe.

The intracoronary administration of streptokinase was associated with cineangiographic evidence of reperfusion, and this led to a resurgence of interest. ${ }^{8.11}$ Relatively few patients, however, can be admitted to hospitals that have facilities for immediate coronary angiography. Moreover, a recent review of published data on the influence of thrombolytic treatment on mortality does not support the belief that intracoronary administration is superior to intravenous administration. ${ }^{12}$ Efficacy and safety may be enhanced by fibrin specific agents that become concentrated at the site of a recent thrombus, thus improving the ratio of local effect to systemic effect. These agents include tissue plasminogen activator, ${ }^{13}{ }^{14}$ prourokinase, ${ }^{15}$ and anisoylated plasminogen streptokinase activator complex (APSAC or BRL 26921). ${ }^{16}$

Royal Sussex County Hospital, Brighton BN2 5BE

S IKRAM, MB, MRCP, research registrar in cardiology S LEWIS, BM, MRCP, registrar in cardiology

C BUCKNALL, MB, MRCP, registrar in cardiology

I SRAM, MB, MRCP, research registrar in cardiology

N THOMAS, BSC, MB, research registrar in cardiology

R VINCENT, MD, FRCP, consultant cardiologist

D CHAMBERLAIN, MD, FRCP, consultant cardiologist

Correspondence to: Dr Chamberlain.
We undertook a trial of APSAC in patients with probable recent myocardial infarction to assess its effects on indices of infarct size.

\section{Patients and methods}

From February 1984 to March 1985, 563 patients admitted to the cardiac care unit with probable myocardial infarction were considered for inclusion in the trial if they were aged under 75 and if treatment could be administered within four hours after the onset of main symptoms. The criteria for probable infarction were characteristic pain of more than 30 minutes' duration and compatible electrocardiographic abnormalities, including ST segment elevation of at least $1 \mathrm{~mm}$ that did not resolve after glyceryl trinitrate was administered sublingually or by spray.

Reasons for patients being excluded from the trial were: onset of main symptoms of infarction was more than four hours previously (207 patients); insufficient electrocardiographic evidence of infarction (213); patient was older than 75 (95); and other reasons (including cardiogenic shock and duodenal ulceration) (112). Some patients were excluded for more than one reason. After completing a check list the remaining 149 patients $(26 \%)$ were grouped according to whether they had had a previous infarction or not (by clinical or electrocardiographic criteria) and whether the onset of their symptoms had occurred within the previous two and a half hours (early entry group) or between two and a half and four hours previously (late entry group). The patients were then randomised within these four subsets by means of sealed envelopes prepared in sets of eight, with similar numbers each receiving APSAC (76) and conventional treatment (73) alone.

Table I shows the grouping of patients into subsets by treatment and time of admission. The number of patients who had had a previous infarction was

TABLE I-Numbers of patients admitted to trial and with confirmed infarction, and their $R$ wave preservation

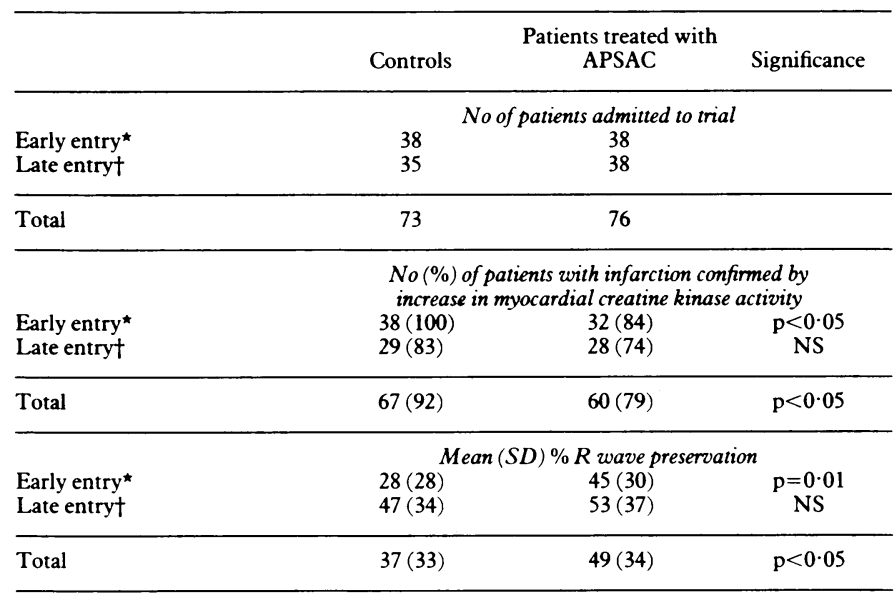

$\star 0-2^{1 / 2}$ hours after infarction. $\nmid 2 \frac{1}{2}-4$ hours after infarction.

too small to justify separate analysis. Subsequent confirmation of acute infarction depended on an increase in plasma activity of myocardial creatine kinase isoenzyme to more than $15 \mathrm{IU}$, three times the upper normal limit for our laboratory. The Norris prognostic index was determined for each patient during randomisation. ${ }^{17}$ The actively managed and control groups were matched for sex, blood pressure on admission, prognostic index, history of angina, previous infarction, hypertension, and diabetes (table II). Only six patients had had previous left ventricular failure.

The design of the trial was open: patients in the control group were not 
given placebo. This was considered to be appropriate because all main end points were objective, and informal consent to use the new treatment was gained only from those in the actively managed group. The consent followed the guidelines for trials in acute illness laid down by the Declaration of Helsinki. A standard dose of 30 units of APSAC was administered intravenously over four minutes. In addition, all patients received conventional treatment together with regular antacid with a low sodium content (Polycrol Forte Gel).

TABLE II-Comparison of clinical data of patients on admission to trial (figures are numbers (\%) of patients except where indicated)

\begin{tabular}{|c|c|c|}
\hline & Controls & $\begin{array}{l}\text { Patients treated } \\
\text { with APSAC }\end{array}$ \\
\hline M:F & $55: 18$ & $60: 16$ \\
\hline Mean age (years) & 61 & 58 \\
\hline Systolic blood pressure $(\mathrm{mm} \mathrm{Hg})$ & 130 & 128 \\
\hline \multicolumn{3}{|l|}{ Coronary prognostic index (Norris): } \\
\hline 1 and 2 & 19 & 21 \\
\hline 3 and 4 & 45 & 44 \\
\hline 5 and 6 & 7 & 9 \\
\hline Not classified & 2 & 2 \\
\hline \multicolumn{3}{|l|}{ Infarct site: } \\
\hline Anterior & 29 & 36 \\
\hline Inferior & 40 & 30 \\
\hline Anterior and inferior & & 2 \\
\hline Unclassified ${ }^{\star / u n k n o w n ~}$ & 4 & 8 \\
\hline \multicolumn{3}{|l|}{ History of: } \\
\hline Angina & $32(46)$ & $30(40)$ \\
\hline Myocardial infarction & $13(18)$ & $15(20)$ \\
\hline Hypertension & $12(16)$ & $14(19)$ \\
\hline Diabetes mellitus & $2(3)$ & $2(3)$ \\
\hline \multirow{2}{*}{$\begin{array}{l}\text { Mean (SD) delay between onset of } \\
\text { symptoms and trial entry (minutes) }\end{array}$} & & \\
\hline & $155(51)$ & $164(47)$ \\
\hline
\end{tabular}

*Unclassified when electrocardiography did not show progress to infarct pattern.

TABLE III-Number (\%) of patients experiencing ventricular tachycardia within four hours of entering trial

\begin{tabular}{lcc}
\hline & $\begin{array}{c}\text { Controls } \\
(\mathbf{n}=65)\end{array}$ & $\begin{array}{c}\text { Patients treated } \\
\text { with APSAC } \\
(\mathbf{n}=68)\end{array}$ \\
\hline $\begin{array}{l}\text { Salvos of 5-10 beats } \\
>10 \text { Beats }\end{array}$ & $24(37)$ & $43(63)$ \\
$8(12)$ \\
\hline
\end{tabular}

TABLE IV-Results of follow up at nine to 12 months (figures are numbers of patients)

\begin{tabular}{lccc}
\hline & Controls & $\begin{array}{c}\text { Patients treated } \\
\text { with APSAC }\end{array}$ & Significance \\
\hline $\begin{array}{l}\text { Readmitted with ischaemic chest pain } \\
\text { Reinfarction }\end{array}$ & 3 & 9 & NS \\
Died: & 1 & 1 & NS \\
$\quad$ In hospital & 7 & 5 & \\
After discharge & 5 & 2 & NS \\
$\quad$ Total & 12 & 7 & . \\
\hline
\end{tabular}

*Seven day mortality was six in control group and three in group treated with APSAC.

We routinely anticoagulate patients in whom there are no contraindications with intravenous heparin over four days. Those who have high serial fibrinogen concentrations - above the upper quartile-also receive warfarin for six weeks. The first dose of heparin was withheld for six hours from the patients in the actively managed group. No other difference in subsequent management was planned, but there was a tendency to recommend coronary angiography more readily in the convalescent phase for those who we believed had had myocardial reperfusion as a result of treatment. This difference occurred after the end points of the trial and therefore could not influence our results. All drugs administered were recorded.

Investigations included registration of heart rate, blood pressure, and respiration every half hour for four hours and every four hours thereafter. Diagnostic electrocardiograms were recorded at presentation, after nitrates had been administered, two to four hours after entry, and daily until discharge. Heart rhythm was recorded on tape for the first 24 hours by Tracker recorders with analysis by a Pathfinder II (Reynolds Medical). Records that were satisfactory for analysis were obtained from 65 control patients and 68 who had received APSAC. Chest radiographs were obtained on entry, at discharge from hospital, and at other times according to clinical indications.

Indices of infarct size depended on enzyme release and preservation of $R$ waves on the electrocardiograms. Blood taken every six hours over 48 hours was used to estimate enzyme activity spectrophotometrically; curves were extrapolated to baseline by regression analysis to obtain final triangulation so that the total myocardial creatine kinase isoenzyme released could be calculated. $R$ wave scores were measured with Yusuf's method. ${ }^{18}$ Vulnerable leads were considered to be those showing more than $1 \mathrm{~mm} \mathrm{ST} \mathrm{segment}$ deviation. In each vulnerable lead the $R$ wave amplitude on discharge from hospital was expressed as a percentage of the corresponding $R$ wave amplitude on the prerandomisation electrocardiogram. The $R$ wave score for each patient was defined as the average of these percentages. Patients who did not show a decrease in $\mathrm{R}$ wave amplitude thus scored $100 \%$, while those who lost all $\mathrm{R}$ waves in vulnerable leads scored $0 \%$. Patients with bundle branch block or major axis deviation were scored arbitrarily at $25 \%$; patients with more than one of these were scored arbitrarily at $10 \%$; and patients who died before the second electrocardiogram were given a score of $0 \%$.

Statistical analysis was performed with Student's unpaired $t$ test or $\chi^{2}$ test as appropriate.

\section{Results}

Tables I and III show the principal results of the trial. Sixty seven of the 73 patients in the control group showed increased activity of myocardial creatine kinase isoenzyme that was diagnostic of infarction, compared with 60 of 76 who received APSAC. The difference was significant overall but occurred predominantly in the early entry group. Similar findings were obtained with $\mathbf{R}$ wave scores, our second index of muscle necrosis. Preservation of $R$ waves in the vulnerable leads was $12 \%$ better overall in the actively managed group $(p<0.05)$; the difference was $17 \%$ in the early entry group $(p<0.01)$ compared with $6 \%$ in the late entry group.

In the first four hours after entry to the trial salvos of ventricular tachycardia of five to 10 beats were more common in the actively managed group than in the control group ( $63 \% v 37 \% ; p<0.05)$. Longer episodes of ventricular tachycardia were equally rare in both groups.

In the early entry group the total myocardial creatine kinase isoenzyme released tended to be smaller $(p=0.2)$ in those treated with APSAC $(1588$ IU) compared with controls (1951 IU), but when only those patients with confirmed infarction were considered there was little difference. Peak myocardial creatine kinase isoenzyme activity was similar in all subsets. The peak was reached earlier in the actively managed group compared with the control group (average 13.9 $v 16$ hours), but the difference, possibly obscured by relatively infrequent sampling, did not reach significance $(p=0 \cdot 11)$.

Four patients were included who did not conform to the criteria for entry to the trial. Two were aged over 75 , one was admitted with severe cardiogenic shock, and in one we were unable to confirm the electrocardiographic criteria for admission. All these patients were in the control group. They have been included in the analysis.

The prevalence of adverse events that could have been due to drug treatment was much higher in the actively managed group (26\%) than in the control group (3\%), but most were trivial. Complications that developed after taking APSAC included bruising (eight patients), nausea and flushing (seven), and minor bleeding (three)-mostly streaks of blood from the mouth or the upper respiratory tract or in vomit. One patient had an unusual shower of emboli to the lower trunk and legs 18 hours after infarction, resulting in numerous patches of skin and muscle necrosis and, ultimately, in gangrene of the toes. His illness had been complicated from the start by refractory pulmonary oedema, and the prognosis was therefore poor; his death three months after the attack might, nevertheless, have been hastened by the emboli. A similar event, however, has been observed since the trial was completed, in a patient who was not treated with a thrombolytic drug.

All patients were followed up at nine to 12 months (table IV). The favourable trend in mortality observed during the first seven days in hospital (six in the control group compared with three in the actively managed group) continued subsequently, the total number of deaths being 12 and seven respectively. There was no difference between the two groups in the number of patients admitted with reinfarction, but more actively managed patients were readmitted with episodes of chest pain. Six patients in the control group and eight in the actively managed group had coronary artery bypass grafts during follow up.

\section{Discussion}

The long latent period before thrombolysis became accepted as a treatment for coronary thrombosis was due to several factors. These 
include disappointing results in trials, ${ }^{67}$ more interest in the role of platelets in the genesis of myocardial infarction, ${ }^{19}$ and, later, even denials that coronary occlusion was an important initiating cause of the illness ${ }^{20}$; all these distracted attention away from the thrombus as a point of therapeutic attack.

The new interest in thrombolysis centred at first on the use of intracoronary streptokinase. The belief that a high local concentration would be most effective seems reasonable, but streptokinase is inert except as an activator of plasminogen, and the plasminogenstreptokinase complex itself serves only to cleave free plasminogen into active plasmin. ${ }^{21}$ This mode of action implies that excess enzyme activity may even have an inhibitory effect on clot dissolution by limiting the availability of free plasminogen. Whether or not direct delivery to the site of action is advantageous the association of angiography with thrombolysis has convinced even sceptics that reperfusion can occur relatively soon after starting treatment with intravenous or intracoronary streptokinase. ${ }^{22}$ The evidence presented by Yusuf et al suggests that the largest reductions in mortality have occurred in trials using intravenous administration. ${ }^{12}$ Although the intracoronary route is likely to be more effective, large scale trials capable of providing firm evidence can more readily be conducted with systemic administration. Indeed, a trial including over 11000 patients recently confirmed the efficacy of intravenous dosage. ${ }^{23}$ Others have used a combination of both routes successfully. ${ }^{24}$

Problems sometimes associated with intravenous thrombolytic agents, especially the pronounced and potentially dangerous systemic thrombolytic state, may be minimised by new fibrin specific agents. APSAC, like tissue plasminogen activator, attains high local concentrations at the site of the clot so that systemic effects are minimised. ${ }^{25}$ These new agents thus combine the advantages of the convenience of intravenous use with the lower risk of haemorrhage that occurs with intracoronary administration. Moreover, both preparations overcome any potential inhibitory effects of excess streptokinase: tissue plasminogen activator contains none and APSAC carries its own plasminogen. In addition, APSAC has a unique advantage - namely, it can be given by syringe over a few minutes yet have a sustained effect over several hours as it becomes deacylated. Tissue plasminogen activator on the other hand has a very short half life and is given by infusion. Thus as well as being convenient APSAC acts over a longer period and offers less opportunity for fresh thrombus formation during a critical time for a damaged artery.

Our trial was designed to determine the effects of APSAC on the evolution of infarction as determined by clinical, electrocardiographic, and biochemical criteria. It was undertaken in a district general hospital that did not have facilities for angiography-the setting in which any successful thrombolytic agent would find greatest use. Other studies, with similar criteria to ours, have shown that APSAC administered within three hours of infarction can achieve clot lysis in up to $80 \%$ of patients. ${ }^{1626}$ Our hope that we may have achieved reperfusion in a comparable proportion seems reasonable, though we have no direct evidence of this. The salvos of ventricular tachycardia were more frequent after thrombolytic treatment, suggesting a reperfusion effect in the actively managed group as a whole, ${ }^{27}$ but arrhythmias are not proof that reperfusion occurred in individual patients. We were unable to monitor accurately differences in the rate of change of ST segment displacement.

Fewer patients treated with APSAC than with conventional treatment developed confirmed infarction as determined by enzyme activity. Early administration of streptokinase can abort potential infarction, ${ }^{28}$ but we doubt if many of our patients were treated quickly enough to achieve this effect. Some may not have been destined to progress from ischaemia to infarction, for diagnosis on the criteria of pain and modest ST segment elevation is not reliable soon after the onset of symptoms. The significantly greater number who did not have infarction in the treated group, however, suggests that reperfusion after thrombolysis at least played a part, perhaps by preventing evolution of threatened infarction rather than reversing an established event. The actively managed group also showed significantly less $\mathrm{R}$ wave loss resulting from ischaemic events.
Most of the apparent benefit occurred in patients admitted to the trial within two and a half hours of the onset of symptoms. This is to be expected, because experimental myocardial necrosis starts within 40 minutes of occlusion of a coronary artery and is more than half complete at three hours. ${ }^{29}$ The time course of clinical infarction may not be very different; moreover, thrombolysis does not occur immediately after the administration of a thrombolytic agent. Thus any benefit from the late administration of APSAC depends on the tendency of the thrombus to extend over hours or days, ${ }^{30}$ increasing the myocardial necrosis; but any such secondary effect could be shown only in a late entry trial with many patients. Effects of the drug on mortality must also be determined by large multicentre trials ${ }^{23}$; the favourable trend in our own study could readily have occurred by chance.

If treatment with APSAC is most likely to benefit patients treated within two or three hours after infarction many will be denied myocardial salvage because of late admission to hospital. In Brighton awareness of the advantages of early admission in the control of ventricular fibrillation has been heightened by the use of resuscitation ambulances ${ }^{31}$ and community education in emergency aid. ${ }^{32}$ Yet even in this setting only half of our patients could be considered for thrombolytic treatment within four hours of the onset of symptoms, some of the delay occurring in hospital. The patients excluded from the trial by the rigid electrocardiographic criteria would not have been denied treatment under usual service conditions if thrombolytic treatment had been proved to be beneficial and safe, but if even half of the patients admitted to hospital with probable infarction are to be treated within the time in which thrombolysis is of some use new ways must be found of encouraging both prompt referral from the community and urgent assessment in emergency or cardiac care units. Alternatively, thrombolytic treatment could in future be given by general practitioners when they diagnose infarction. The unique combination of efficacy with intravenous hand injection and safety from slow deacylation and fibrin specificity suggests that APSAC may be the most suitable of the agents currently available for the prehospital phase.

The benefits of thrombolysis in acute infarction may not last. The incidence of reinfarction after treatment with streptokinase ${ }^{33}$ and tissue plasminogen activator ${ }^{13}$ is appreciable. The benefits recorded early during follow up in one of the best trials of intracoronary streptokinase $^{11}$ had diminished considerably when follow up was extended to a minimum of 12 months for all those who participated. ${ }^{34}$ Coronary angiography for all who have received thrombolytic treatment is impractical in Britain, so methods must be sought for selecting those patients at high risk of recurrence.

Much remains to be done before the role of thrombolytic agents can be adequately defined, but we have hope in the fibrin specific agents of new treatments for myocardial infarction that are effective and safe. The knowledge that successful treatment of primary ventricular fibrillation could reduce mortality only within three or four hours of acute infarction failed to stimulate an urgent review of admission procedures. We hope that the potential benefits of thrombolysis may stimulate a better response.

We are grateful to our colleagues who allowed us to include in the study patients admitted under their care; to the junior medical staff who completed complex admission forms; and especially to the nurses who spent many hours helping with electrocardiograms and blood samples. Clerical help was given by Mrs E Quinn, who is supported by a grant from the South East Thames Regional Health Authority.

\section{References}

1 DeWood MA, Spores J, Notske R, et al. Prevalence of total coronary occlusion during the early hours of transmural myocardial infarction. $N$ Engl f Med 1980;303:897-902.

2 Davies MJ, Thomas AC. Plaque fissuring-the cause of acute myocardial infarction, sudden ischaemic death, and crescendo angina. Br Heart $\mathcal{F}$ 1985;53:363-73.

3 Fletcher AP, Sherry S, Alkjaersig N, Smyrniotis FE, Jick S. The maintenance of a sustained thrombolytic state in man. II. Clinical observations on patients with myocardial infarction and other thrombo-embolic disorders. F Clin Invest 1959;38:1111-9.

4 Schmutzler R, Heckner F, Kortge P, et al. Thrombolytic therapy of recent myocardial infarction Disch Med Wochenschr 1966;91:581-7. 
5 European Working Party. Streptokinase in recent myocardial infarction: a controlled multicentre trial. BrMed f 1971;iii:325-31.

6 Bett JHN, Biggs JC, Castaldi PA, et al. Australian multicentre trial of streptokinase in acute myocardial infarction. Lancet 1973; ; $: 57-60$

7 Aber CP, Bass NM, Berry CL, et al. Streptokinase in acute myocardial infarction: a controlled multicentre study in the United Kingdom. Br Med F 1976;ii:1100-4.

8 Rentrop KP, Blanke $\mathrm{H}$, Karsch KR, et al. Acute myocardial infarction: intracoronary application of nitroglycerin and streptokinase. Clin Cardiol 1979;2:354-63.

9 Fioretti P, Simoons ML, Serruys PW, van den Brand M, Fels PW, Hugenholtz PG. Clinical course after attempted thrombolysis in myocardial infarction. Eur Heart $\mathcal{f}$ 1982;3:422-32.

$10 \mathrm{Khaja} \mathrm{F}$, Walton JA, Brymer JF, et al. Intracoronary fibrinolytic therapy in acute myocardial infarction. Report of a prospective randomised trial. N Engl f Med 1983;308:1305-11.

11 Kennedy JW, Ritchie JL, Davis KB, Fritz JK. Western Washington randomised trial of intracoronary streptokinase in acute myocardial infarction. N Engl f Med 1983;309:1477-82.

12 Yusef S, Collins R, Peto R, et al. Intravenous and intracoronary fibrinolytic therapy in acute myocardial infarction: overview of results on mortality, reinfarction and side-effects from 33 randomised controlled trials. Eur Heart f 1985;6:556-85.

13 TIMI Study Group. Special report. The thrombolysis in myocardial infarction (TIMI) trial. Phase 1 findings. N Engl f Med 1985;312:932-6.

14 Verstraete M, Bernard R, Bory M, et al. Randomised trial of intravenous recombinant tissue-type plasminogen activator versus intravenous streptokinase in acute myocardial infarction. Lancet plasminogen $1985 ;$ i: $842-7$.

15 Gurewich V, Pannell R, Louie S, Kelley P, Suddith RL, Greenlee R. Effective and fibrin-specific clot lysis by a zymogen precursor form of urokinase (pro-urokinase). 7 Clin Invest 1984;73: $1731-9$.

16 Been M, de Bono DP, Muir AL, Boulton FE, Hillis WS, Hornung R. Coronary thrombolysis with intravenous anisolylated plasminogen streptokinase complex BRL 26921. Br Heart f 1985;53: 253-9.

17 Norris RM, Brandt PWT, Caughey DE, Lee AJ, Scott PJ. A new coronary prognostic index. Lancet 1969;i:274-8.

18 Yusuf S, Ramsdale D, Peto R, et al. Early intravenous atenolol treatment in suspected acute myocardial infarction. Lancet 1980; i:273-6.

19 Hampton JR, Gorlin R. Platelet studies in patients with coronary artery disease and in their relatives. Br Heari f 1972;34:465-71.

20 Silver MD, Baroldi G, Mariani F. The relationship between acute occlusive coronary thrombi and myocardial infarction studied in 100 consecutive patients. Circulation 1980;61:219-27.
21 Tiefenbrunn AJ, Sobel BE. Tissue-type plasminogen activator (t-PA): an agent with promise for selective thrombolysis. Int $\mathcal{F}$ Cardiol 1985; 7:82-6.

22 Schroder R, Biamino G, Leitner EV, et al. Intravenous short-term infusion of streptokinase in acute myocardial infarction. Circulation 1983;67:536-48.

23 Gruppo Italiano per lo studio della streptochinasi nell'infarto miocardico(GISSI). Effectiveness of intravenous thrombolytic treatment in acute myocardial infarction. Lancet 1986;i:397-402.

24 Simoons ML, Serruys PW, vd Brand M, et al. Improved survival after early thrombolysis in acute myocardial infarction. Lancet 1985; ii:578-82.

25 Smith RAG, Dupe RJ, English PD, Green J. Fibrinolysis with acyl-enzymes: a new approach to thrombolytic therapy. Nature 1981;290:505-8.

26 Been M, de Bono DP, Muir AL, et al. Clinical effects and kinetic properties of intravenous APSAC_-anisoylated plasminogen-streptokinase activator complex (BRL 26921) in acute myocardial infarction. Int $\mathcal{f}$ Cardiol (in press).

27 Ganz W, Geft I, Shah PK, et al. Intravenous streptokinase in evolving acute myocardial infarction Am f Cardiol 1984;53:1209-16.

28 Davies GJ, Chierchia S, Maseri A. Prevention of myocardial infarction by very early treatmen with intracoronary streptokinase. Some clinical observations. N Engl f Med 1984;311:1488-92.

29 Reimer KA, Lowe JE, Rasmussen MM, Jennings RB. The wavefront phenomenon of ischemic cell death 1 . Myocardial infarct size vs duration of coronary occlusion in dogs. Circulation 1977;56:786-94

30 Erhardt LR, Unge G, Boman G. Formation of coronary arterial thrombi in relation to onset of necrosis in acute myocardial infarction in man. A clinical and autoradiographic study. Am Heart f 1976;91:592-8.

31 O'Doherty M, Tayler DI, Quinn E, Vincent R, Chamberlain DA. Five hundred patients with myocardial infarction monitored within one hour of symptoms. Br Med f 1983;286:1405-8.

32 Vincent R, Martin B, Williams G, Quinn E, Robertson, G, Chamberlain DA. A community training scheme in cardiopulmonary resuscitation. $\mathrm{Br}$ Med f 1984;288:617-20.

33 Schroder R, Vohringer H, Linderer T, Biamino G, Bruggemann T, Leitner EV. Follow-up after coronary arterial reperfusion with intravenous streptokinase in relation to residual myocardia infarct artery narrowings. Am $\mathcal{F}$ Cardiol 1985;55:313-7.

34 Kennedy JW, Ritchie JL, Davis KB, Stadius ML, Maynard C, Fritz JK. The Western Washington randomized trial of intracoronary streptokinase in acute myocardial infarction. A 12-month follow-up report. N Engl f Med 1985;312:1073-8.

(Accepted 3 fuly 1986)
The incidence of cryptorchidism, with its associated increased risk of subfertility and testicular malignancy, ${ }^{12}$ seems to be increasing. ${ }^{3}$ Scorer and Farrington carried out a study of the incidence of cryptorchidism in the late 1950 s. ${ }^{1}$ Any boy found to be cryptorchid at birth was examined at 3 months of age and, if still cryptorchid then, at 1 year of age. Those boys whose testes were descended either at birth or at 3 months were not re-examined. Only if the testes were still undescended at the age of 1 was the boy considered to be truly cryptorchid; this approach has been generally accepted by paediatric surgeons.

In their study of a group of boys born in the mid to late 1950s Scorer and Farrington found that $0.8 \%$ were truly cryptorchid. ' Data from the Hospital Inpatient Enquiry, however, show that about $1.9 \%$ of the same cohort of boys underwent orchidopexy. ${ }^{3}$ It has been argued that the additional boys undergoing orchidopexy represent those who were misdiagnosed cases of retractile testes. ${ }^{4}$ We believe that we have identified the major source of these cases.

\section{Patients and methods}

As part of a long term prospective study all boys born in the John Radcliffe Hospital, Oxford, are examined at birth. Boys who are cryptorchid are reexamined at 3 months of age or, in the case of premature infants, 3 months after their expected date of delivery. A cryptorchid testis is defined as one where the centre of the testicle is less than $4 \mathrm{~cm}$ below the pubic tubercle $(2.5 \mathrm{~cm}$ for babies weighing less than $2500 \mathrm{~g}$ ) when measured at its lowest point after manipulation but without applying tension.' All cryptorchid testes are then classified as either non-scrotal or scrotal. A non-scrotal cryptorchid testis is one which is always found outside the scrotum and cannot be manipulated into the scrotum without tension. A scrotal cryptorchid testis is one which may not be found in the scrotum but can be manipulated into the scrotum without tension, although it remains less than $4 \mathrm{~cm}$ below the pubic tubercle.

\section{Results}

We examined at around 1 year of age the first 45 boys (who had not moved out of the area) whose testes were descended at the 3 month examination but not at birth-described as late descenders-and a group of 20 control babies whose testes were descended at birth.

The testes of all the 20 control babies were still descended at 1 year. In contrast, of the 45 late descenders, $18(40 \%)$ had a cryptorchid testis at 1 year; the least descended testis was in a non-scrotal position in $14(78 \%)$ of these 18 boys. A high proportion $(29(64 \%))$ of the late descenders had had bilateral undescended testes at birth, and these boys had a slightly decreased risk of being cryptorchid at 1 year $(10 / 29(34 \%)$ compared with $8 / 16(50 \%))$. We also recorded the presence of other anatomical abnormalities in these boys and found a hydrocele either at birth or at 3 months in seven $(39 \%)$ of the 18 late descenders who had a cryptorchid testis at 1 year, compared with five (19\%) of the 27 who did not.

\section{Comment}

These late descenders whose testes then appear to develop true cryptorchidism probably explain the discrepancy between the $0.8 \%$ of boys identified with a true cryptorchidism in 1960 and the $1.9 \%$ who underwent orchidopexy. ${ }^{13}$

The term retractile testis describes a testis that is drawn up into the superficial inguinal pouch by the cremasteric muscle. We believe that this term is not appropriate for the late descended testes which are then found to be cryptorchid at 1 year. These testes are normally outside the scrotum and can be manipulated only with great difficulty into the scrotum under tension.

A possible explanation for this finding is that cryptorchidism may be acquired after birth by the resorption of an occult inguinal hernia. ${ }^{5}$ Although we found no frank hernias in any of these 45 boys, a hydrocele was found in high proportion of the group with late descending testes that were cryptorchid at 1 year.

Screening between birth and school age in Britain is designed to detect all cases of undescended testis. Our results suggest than any baby whose testes are not descended at birth should be examined again at 3 months and again at 1 year. Whether a late descending testis that becomes cryptorchid again requires treatment is not known.

PA and AP re-examined the babies at 12 months. This report was prepared by $\mathrm{PA}, \mathrm{MBJ}, \mathrm{MCP}$, and $\mathrm{CC}$.

This study is funded by the Imperial Cancer Research Fund, through its Cancer Epidemiology Unit, and by the Cancer Research Campaign and Medical Research Council through their grant to the Institute of Cancer Research.

1 Scorer CG, Farrington GH. Congenital deformities of the testis and epididymis. London: Butterworths, 1971:15-27.

2 Chilvers C, Dudley NE, Gough MH, Jackson MB, Pike MC. Undescended testis: and malignancy. $\exists$ Pediatr Surg (in press). 